\title{
Evaluation and Elucidation of Bioactive Compounds from Leptogium rivurale Through in-vitro and in-silico Studies ${ }^{\dagger}$
}

\author{
Prakash P. ${ }^{1, *}$, Bommana Chanakya ${ }^{1}$, Guraja Sreeja ${ }^{1}$, Amritha Harini ${ }^{1}$ \\ 1 Department of Biotechnology, Sathyabama Institute of Science and Technology, Chennai, Tamil Nadu, India \\ * Correspondence: kpprakashmtech@gmail.com; \\ $\dagger$ Presented at International e-Conference on Bioengineering for Health and Environment (ICBHE 2020)
}

Received: 5.07.2020; Revised: 10.07.2020; Accepted: 12.07.2020; Published: 15.07.2020

\begin{abstract}
Leptoguium rivurale is a flooded jelly skin lichen, the surface of which becomes jelly when wet. It is a cyanolichen in which the photosynthetic partner is a cyanobacterium in the genus name Nostac. The present study was performed to investigate the bioactive constituents of Leptoguium rivurale. Samples were collected from forest regions of Kodaikanal. The collected Lichens were washed and dried and then extracted by using methanol and distilled water. Qualitative analysis of phytochemicals from the extracts showed the presence of carbohydrates, glycosides, phenols, terpenoids, saponins, and proteins. The amount of carbohydrates, phenols, and proteins was found to $350 \mathrm{u} / \mathrm{g}$ and $380 \mathrm{u} / \mathrm{g}, 200 \mathrm{u} / \mathrm{g}$, and $240 \mathrm{u} / \mathrm{g}$ and $490 \mathrm{u} / \mathrm{g}$ and $320 \mathrm{u} / \mathrm{g}$ in aqueous and methanol extracts. The $\alpha$-amylase enzyme inhibition assay ranged from $47.2 \%$ to $58.4 \%$ for methanol extract and from $35.12 \%$ to $51.1 \%$ for aqueous extract. The DPPH radical scavenging activity ranged from $27.6 \%$ to $49.8 \%$ for methanol extract and from $21.3 \%$ to $42.2 \%$ for aqueous extract. The anti-inflammatory activity ranged from $40.5 \%$ to $86.2 \%$ for methanol extract and from $49.4 \%$ to $79.2 \%$ for aqueous extract. Then the extract was given for GC-MS analysis. The molecules that were obtained in this analysis were used as ligands and in-silico molecular docking simulation was made using AutoDock software through which it was found that out of the docked ligands cyclohexanol and oxirane were the potential drug candidates.
\end{abstract}

Keywords: Leptoguium rivurale; phytochemicals; anti-inflammatory activity; AutoDock software.

(C) 2020 by the authors. This article is an open-access article distributed under the terms and conditions of the Creative Commons Attribution (CC BY) license (https://creativecommons.org/licenses/by/4.0/).

\section{Funding}

This research received no external funding.

\section{Acknowledgments}

This research has no acknowledgment.

\section{Conflicts of Interest}

The authors declare no conflict of interest. 